\title{
The effect of emotional intelligence and job satisfaction on organizational citizenship behavior
}

\author{
Amir Hoshang Sabahi* and Naser Sanai Dashti
}

Department of Management and Accounting, Central Branch, Islamic Azad University, Tehran, Iran

\begin{tabular}{l}
\hline C H R O N I C L E \\
\hline Article history: \\
Received January 5, 2016 \\
Received in revised format April \\
15,2016 \\
Accepted June 2, 2016 \\
Available online \\
June 2, 2016 \\
\hline Keywords: \\
OCB \\
Emotional Intelligence \\
Job satisfaction \\
Organizational citizenship \\
behavior
\end{tabular}

\section{Introduction}

Several evidences suggest that individuals who are high in emotional intelligence are more likely to perform a higher level of performance outcomes. Carmeli and Josman (2006) investigated the relationship between emotional intelligence (BarYOn, 2000) and two characteristics of work outcomes including task performance and two types of organizational citizenship behaviors, altruism and compliance an reported positive relationships between emotional intelligence and employees' work outcomes. Appelbaum et al. (2004) developed an action plan to move from current culture to preferred expressed culture beginning by rewarding team activity rather than individual activities; improving employee satisfaction even if the observed level were medium to high. Bienstock et al. (2003) studied organizational citizenship behavior, with its framework of organizational rights and responsibilities. The study indicated that service employee perceptions were positively associated with organizational citizenship behaviors. In addition, it showed that these behaviors could yield in more effective service delivery to organizational standards and enhanced customer perceptions of service quality. Bolino and

* Corresponding author. Tel.: +989181111607

E-mail address: amir.sabahi123@gmail.com (A. H. Sabahi)

C 2016 Growing Science Ltd. All rights reserved. doi: $10.5267 /$ j.msl.2016.6.001 
Turnley (2003) provided an overview of the issues that are responsible for producing citizenship behaviors and described how different firms could develop practices that foster and sustain employee citizenship. They also explained how citizenship behaviors should be monitored and managed in order for such behaviors to have enhancing rather than deleterious impacts on organizational and employee performance.

Jung and Yoon (2012) performed an investigation to understand the interrelationships among the emotional intelligence of employees in a deluxe hotel, their counterproductive work behaviors, and organizational citizen behaviors in Korea. The results indicated that as elements of emotional intelligence, others' emotion appraisal, use of emotion, and self-emotion appraisal significantly influenced on counterproductive work behaviors, whereas self-emotion appraisal and use of emotion influenced on organizational citizen behaviors. Chiu and Chen (2005) reported that job variety and job significance influenced positively on OCB, whereas job identity, job autonomy, job feedback and job interdependence were not substantially associated with OCB. In addition, in their survey, job satisfaction, especially intrinsic satisfaction, was a mediating mechanism of the relationship between job variety, job significance and OCB.

\section{The proposed study}

This paper presents an empirical investigation to study the roles of emotional intelligence (EI) and job satisfaction (JS) (Bateman \& Organ, 1983) on employees' organizational citizenship behavior (OCB). (Brightman \& Moran, 1999; Barroso Castro et al., 2004). The study is performed among some randomly selected employees who worked for an Iranian bank in province of Karaj in 2014. The sample size of the proposed study is calculated as follows,

$$
n=\frac{N \times z_{\alpha / 2}^{2} \times p \times q}{\varepsilon^{2} \times(N-1)+z_{\alpha / 2}^{2} \times p \times q},
$$

where $N$ is the population size, $p=1-q$ represents the yes/no categories, $z_{\alpha / 2}$ is CDF of normal distribution and finally $\varepsilon$ is the error term. Since we have $p=0.5, z_{\alpha / 2}=1.96$ and $N=230$, the number of sample size is calculated as $n=140$. Fig. 1 shows the structure of the proposed study.

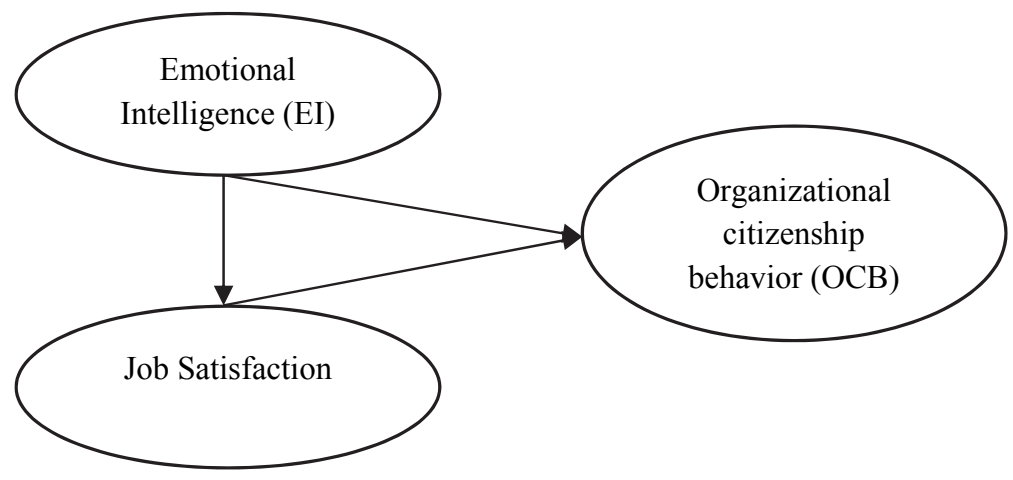

Fig. 1. The structure of the proposed study

There are two main hypotheses associated with the proposed study of this paper as follows,

1. There is a relationship between emotional intelligence and job satisfaction.

2. There is a relationship between job satisfaction and organizational citizenship behavior. 
The study uses the questionnaire developed by Organ (1998) to measure organizational citizenship behavior (OCB). To measure emotional intelligence, the study uses Cyberia Shrink emotional intelligence quiz. Finally, to measure job satisfaction, the study uses a revised version of the questionnaire introduced by Smith et al. (1969).

\subsection{Personal characteristics of the participants}

In our survey, $88 \%$ of the participants were married, $12 \%$ of them were single and nearly $75 \%$ of them were aged 30-40. In addition, about $92 \%$ of the participants hold some university education with good job experiences. Fig. 2 shows some of the personal characteristics of the participants.

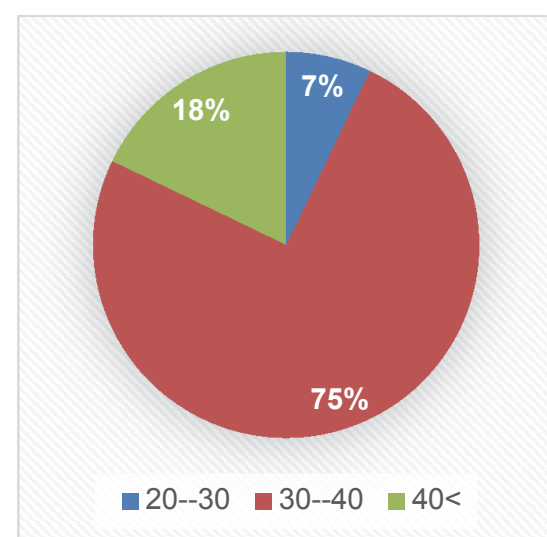

Age

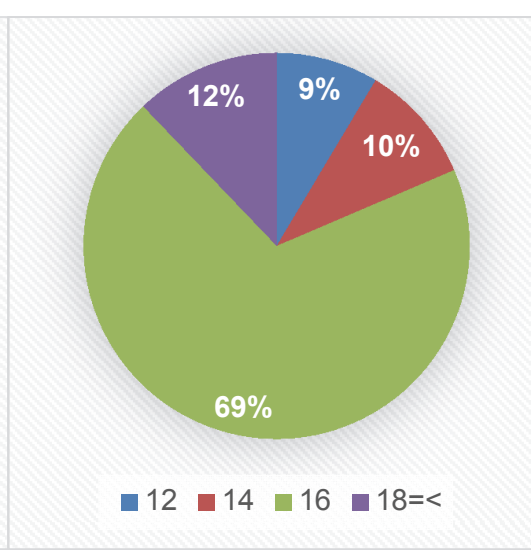

Years of education

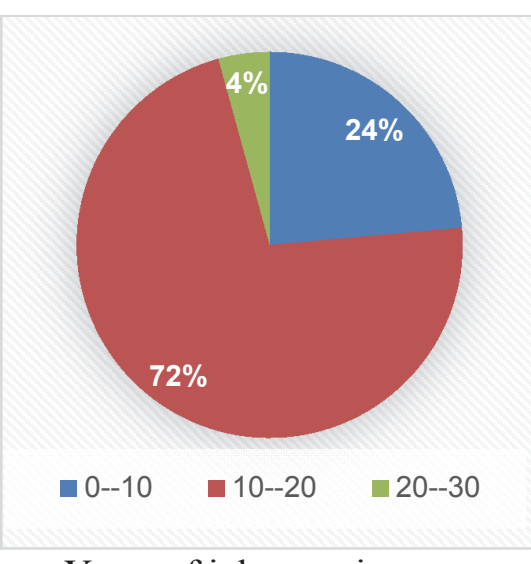

Years of job experience

Fig. 1. Personal characteristics of the participants

Table 1 shows the results of some basic statistics associated with the proposed study. In addition, the implementation of Kolmogorov-Smirnov test has indicated that all three variables of the proposed study are normally distributed when the level of significance was five percent.

\section{Table 1}

The results of some basic statistics

\begin{tabular}{lccc}
\hline Variable & Mean & Variance & Standard deviation \\
\hline Job Satisfaction & 68.89 & 68.265 & 29.16 \\
Nature of work & 30.2 & 71.14 & 3.83 \\
Supervisor & 35.19 & 1.14 & 3.74 \\
Partners & 68.21 & 44.14 & 3.8 \\
Promotion & 72.14 & 83.3 & 5.55 \\
Pay & 62.13 & 60.23 & 85.4 \\
\hline Emotional Intelligence & 55.117 & 28.195 & 9713 \\
Self-motivation & 30.24 & 79.9 & 3.13 \\
Self-awareness & 51.3 & 42.16 & 5.4 \\
Self-control & 52.23 & 19.24 & 4.91 \\
Social consciousness & 34.21 & 30.15 & 3.91 \\
Social skills & 86.17 & 8.11 & 3.32 \\
\hline Organizational citizenship behavior & 34.92 & 39.16 & 25.6 \\
\hline
\end{tabular}

\section{Table 2}

The summary of the implementation of Kolmogorov-Smirnov test

\begin{tabular}{lcccc}
\hline Variable & N & Z & Sig & Result \\
\hline Emotional intelligence & 140 & 0.742 & 0.641 & Normally distributed \\
Job satisfaction & 140 & 0.803 & 0.539 & Normally distributed \\
Organizational citizenship behavior & 140 & 0.948 & 0.330 & Normally distributed \\
\hline
\end{tabular}




\section{The results}

In this section, we present the results of testing different hypotheses of the survey. Table 3 also shows the results of Pearson correlation ratios between emotional intelligence and its factors on one side and organizational citizenship behavior. As we can observe, there are some positive and meaningful relationships between different components and we can conclude that there was a strong and positive relationship between EI and OCB $(r=0.976$, Sig. $=0.000)$.

Table 3

The results of Pearson correlation between emotional intelligence and organizational citizenship behavior

\begin{tabular}{lcccccccc}
\hline & & OCB & $\begin{array}{c}\text { Self- } \\
\text { motivation }\end{array}$ & $\begin{array}{c}\text { Self- } \\
\text { awareness }\end{array}$ & $\begin{array}{c}\text { Self- } \\
\text { control }\end{array}$ & $\begin{array}{c}\text { Social } \\
\text { consciousness }\end{array}$ & $\begin{array}{c}\text { Social } \\
\text { skills }\end{array}$ & $\begin{array}{c}\text { EI } \\
\text { OCB }\end{array}$ \\
& $\mathrm{r}$ & 1 & $0.699^{* *}$ & $0.610^{* *}$ & $0.809^{* *}$ & $0.783^{* *}$ & $0.584^{* *}$ & $0.976^{* *}$ \\
& $\mathrm{sig}$ & & 0.000 & 0.000 & 0.000 & 0.000 & 0.000 & 0.000 \\
\hline Self-motivation & $\mathrm{r}$ & $0.699^{* *}$ & 1 & $0.341^{* *}$ & $0.557^{* *}$ & $0.480^{* *}$ & $0.262^{* *}$ & $0.716^{* *}$ \\
& $\mathrm{sig}$ & 0.000 & & 0.000 & 0.000 & 0.000 & 0.002 & 0.000 \\
\hline Self-awareness & $\mathrm{r}$ & $0.610^{* *}$ & $0.341^{* *}$ & 1 & $0.395^{* *}$ & $0.323^{* *}$ & $0.214^{*}$ & $0.647^{* *}$ \\
& $\mathrm{sig}$ & 0.000 & 0.000 & & 0.000 & 0.000 & 0.011 & 0.000 \\
\hline \multirow{2}{*}{ Self-control } & $\mathrm{r}$ & $0.809^{* *}$ & $0.557^{* *}$ & $0.395^{* *}$ & 1 & $0.609^{* *}$ & $0.277^{* *}$ & $0.828^{* *}$ \\
& $\mathrm{sig}$ & 0.000 & 0.000 & 0.000 & & 0.000 & 0.001 & 0.000 \\
\hline Social & $\mathrm{r}$ & $0.783^{* *}$ & $0.480^{* *}$ & $0.323^{* *}$ & $0.609^{* *}$ & 1 & $0.429^{* *}$ & $0.798^{* *}$ \\
consciousness & $\mathrm{sig}$ & 0.000 & 0.000 & 0.000 & 0.000 & & 0.000 & 0.000 \\
\hline \multirow{2}{*}{ Social skills } & $\mathrm{r}$ & $0.584^{* *}$ & $0.262^{* *}$ & $0.214^{*}$ & $0.277^{* *}$ & $0.429^{* *}$ & 1 & $0.577^{* *}$ \\
& $\mathrm{sig}$ & 0.000 & 0.002 & 0.011 & 0.001 & 0.000 & 0.000 \\
\hline Emotional & $\mathrm{r}$ & $0.976^{* *}$ & $0.716^{* *}$ & $0.647^{* *}$ & $0.828^{* *}$ & $0.798^{* *}$ & $0.577^{* *}$ & 1 \\
Intelligence (EI) & $\mathrm{sig}$ & 0.000 & 0.000 & 0.000 & 0.000 & 0.000 & 0.000 & 0.000
\end{tabular}

Table 4 demonstrates the results of relationships between job satisfaction and organizational citizenship behavior. Again, we observe a positive and meaningful relationships between organizational citizenship behavior and job satisfaction $(r=0.978$, Sig. $=0.000)$.

Table 4

The results of Pearson correlation between job satisfaction (JS) and organizational citizenship behavior

\begin{tabular}{|c|c|c|c|c|c|c|c|c|}
\hline & & $\mathrm{OCB}$ & Nature of & Supervisor & Partners & Promotion & Pay & JS \\
\hline \multirow[t]{2}{*}{ OCB } & $\mathrm{r}$ & 1 & $0.699^{* * * * *}$ & $0.730^{* * *}$ & $0.704^{\text {**: }}$ & $0.841^{\text {**: }}$ & $0.655^{\text {\%** }}$ & $0.978^{\text {*: }}$ \\
\hline & sig & & 0.000 & 0.000 & 0.000 & 0.000 & 0.000 & 0.000 \\
\hline \multirow{2}{*}{$\begin{array}{c}\text { Nature of } \\
\text { work }\end{array}$} & $r$ & $0.699^{\text {絭綵 }}$ & 1 & $0.509^{* * *}$ & $0.489^{\text {\%** }}$ & $0.466^{\text {藻 }}$ & $0.379^{\text {䄅䅈 }}$ & $0.738^{\text {**: }}$ \\
\hline & sig & 0.000 & & 0.000 & 0.000 & 0.000 & 0.000 & 0.000 \\
\hline \multirow[t]{2}{*}{ Supervisor } & $\mathrm{r}$ & $0.730^{* * * *}$ & $0.509^{* * * *}$ & 1 & $0.570^{* * *}$ & $0.540^{* * *}$ & $0.240^{\text {*** }}$ & $0.738^{* * *}$ \\
\hline & sig & 0.000 & 0.000 & & 0.000 & 0.000 & 0.004 & 0.000 \\
\hline \multirow[t]{2}{*}{ Partners } & $r$ & $0.704^{\text {*** }}$ & $0.489^{\text {**** }}$ & $0.570^{\text {*** }}$ & 1 & $0.557^{\text {*** }}$ & $0.283^{\text {*** }}$ & $0.753^{\text {**: }}$ \\
\hline & sig & 0.000 & 0.000 & 0.000 & & 0.000 & 0.001 & 0.000 \\
\hline \multirow[t]{2}{*}{ Promotion } & $r$ & $0.841^{\text {*: }}$ & $0.466^{\text {**:* }}$ & $0.540^{\text {**: }}$ & $0.557^{\text {絭 }}$ & 1 & $0.443^{* * *}$ & $0.836^{\text {**: }}$ \\
\hline & sig & 0.000 & 0.000 & 0.000 & 0.000 & & 0.000 & .0000 \\
\hline \multirow[t]{2}{*}{ Pay } & $r$ & $0.655^{\text {*** }}$ & $0.379^{\text {***: }}$ & $0.240^{\text {** }}$ & $0.283^{\text {**: }}$ & $0.443^{* * *}$ & 1 & $0.659^{\text {**: }}$ \\
\hline & sig & .0000 & 0.000 & 0.004 & .0010 & 0.000 & & 0.000 \\
\hline Job & $r$ & $0.978^{\text {絭 }}$ & $0.738^{\text {**: }}$ & $0.738^{\text {*** }}$ & $0.753^{\text {*** }}$ & $0.836^{\text {*** }}$ & $0.659^{\text {*** }}$ & 1 \\
\hline satisfaction & sig & 0.000 & 0.000 & 0.000 & 0.000 & 0.000 & 0.000 & \\
\hline
\end{tabular}

Table 5 demonstrates the results of step-wise regression model between OCB as dependent variable and emotional intelligence components as independent variables. As we can observe F-value is statistically significant, which means there are some linear and meaningful relationships between OCB and EI components. Durbin-Watson is within desirable level, which means there is no autocorrelation among residuals and finally, Adjusted R-Square is equal to 0.953 , which means independent variables could describe $95 \%$ of the changes on dependent variable. Moreover, all t-values are statistically significant and we can conclude that all EI components positively influence on OCB. 
Table 5

The summary of regression analysis between EI and OCB

\begin{tabular}{|c|c|c|c|c|c|}
\hline \multirow{2}{*}{ Model } & \multicolumn{2}{|c|}{ Non-standard coefficient } & \multirow{2}{*}{$\begin{array}{c}\text { Standard } \\
\text { Beta }\end{array}$} & \multirow{2}{*}{ t-value } & \multirow{2}{*}{ Sig. } \\
\hline & $\mathrm{B}$ & Std. Error & & & \\
\hline Intercept & -16.092 & 1.140 & & -14.116 & 0.000 \\
\hline Self-motivation & 0.437 & 0.046 & 0.219 & 9.517 & 0.000 \\
\hline Self-awareness & 0.392 & 0.032 & 0.254 & 12.411 & 0.000 \\
\hline Self-control & 0.445 & 0.033 & 0.349 & 13.635 & 0.000 \\
\hline Social consciousness & 0.437 & 0.040 & 0.273 & 10.852 & 0.000 \\
\hline Social skills & 0.485 & 0.039 & 0.258 & 12.581 & 0.000 \\
\hline
\end{tabular}

Finally, we study the relationship between job satisfaction and organizational citizenship behavior and Table 6 shows the results of our survey.

Table 6

The summary of regression analysis between JS and OCB

\begin{tabular}{|c|c|c|c|c|c|}
\hline \multirow{2}{*}{ Model } & \multicolumn{2}{|c|}{ Non-standard coefficient } & \multirow{2}{*}{$\frac{\text { Standard }}{\text { Beta }}$} & \multirow{2}{*}{ t-value } & \multirow{2}{*}{ Sig. } \\
\hline & $\mathrm{B}$ & Std. Error & & & \\
\hline Intercept & 2.702 & 0.742 & & 3.643 & 0.000 \\
\hline Nature of work & 0.316 & 0.035 & 0.194 & 9.049 & 0.000 \\
\hline Supervisor & 0.430 & 0.038 & 0.257 & 11.339 & 0.000 \\
\hline Partners & 0.264 & 0.037 & 0.160 & 7.088 & 0.000 \\
\hline Promotion & 0.439 & 0.026 & 0.389 & 16.812 & 0.000 \\
\hline Pay & 0.389 & 0.025 & 0.302 & 15.532 & 0.000 \\
\hline
\end{tabular}

As we can observe F-value is statistically significant, which means there are some linear and meaningful relationships between OCB and JS components. Durbin-Watson is within desirable level, which means there is no autocorrelation among residuals and finally, Adjusted R-Square is equal to 0.96 , which means independent variables could describe $96 \%$ of the changes on dependent variable. Moreover, all t-values are statistically significant and we can conclude that all JS components positively influence on OCB.

\section{Conclusion}

This paper has presented an empirical investigation to study the roles of emotional intelligence (EI) and job satisfaction (JS) on employees' organizational citizenship behavior (OCB) on selected employees who worked for an Iranian bank in province of Karaj. The results of Pearson correlation have indicated that there were some positive and meaningful relationships between EI as well as JS with OCB. In addition, the results of Stepwise regression have indicated that there were some positive and meaningful relationship between all components of EI and JS with OCB. The results of this survey are consistent with other findings reported on the literature (Bateman \& Organ, 1983; Barroso Castro et al., 2004; Carmeli \& Josman, 2006).

\section{Acknowledgement}

The authors would like to thank the anonymous referees for constructive comments on earlier version of this paper.

\section{References}

Appelbaum, S., Bartolomucci, N., Beaumier, E., Boulanger, J., Corrigan, R., Doré, I., ... \& Serroni, C. (2004). Organizational citizenship behavior: a case study of culture, leadership and trust. Management decision, 42(1), 13-40.

BarYOn, R. (2000). Emotional and social intelligence: insights from the Emotional Quotient Inventory. W: R. BarYOn, JDA Parker (red.). The handbook of emotional intelligence, 363 Y388. 
Barroso Castro, C., Martín Armario, E., \& Martín Ruiz, D. (2004). The influence of employee organizational citizenship behavior on customer loyalty. International Journal of Service Industry Management, 15(1), 27-53.

Bateman, T. S., \& Organ, D. W. (1983). Job satisfaction and the good soldier: The relationship between affect and employee "citizenship". Academy of Management Journal, 26(4), 587-595.

Bienstock, C. C., DeMoranville, C. W., \& Smith, R. K. (2003). Organizational citizenship behavior and service quality. Journal of Services Marketing, 17(4), 357-378.

Bolino, M. C., \& Turnley, W. H. (2003). Going the extra mile: Cultivating and managing employee citizenship behavior. The Academy of Management Executive, 17(3), 60-71.

Brightman, B. K., \& Moran, J. W. (1999). Building organizational citizenship. Management Decision, 37(9), 678-685.

Carmeli, A., \& C., Josman, Z. E. (2006). The relationship among emotional intelligence, Task performance and organizational citizenship behavior. Human performance, 19(4), 403-419.

Chiu, S. F., \& Chen, H. L. (2005). Relationship between job characteristics and organizational citizenship behavior: The mediational role of job satisfaction. Social Behavior and Personality: an International Journal, 33(6), 523-540.

Jung, H. S., \& Yoon, H. H. (2012). The effects of emotional intelligence on counterproductive work behaviors and organizational citizen behaviors among food and beverage employees in a deluxe hotel. International Journal of Hospitality Management, 31(2), 369-378.

Organ, D. (1988). Organizational citizenship behavior: The good soldier syndrome. Lexington, MA: Lexington Books.

Smith, P. C., Kendall, L. M., \& Hulin, C. L. (1969). The Measurement of Satisfaction in Work and Retirement. Chicago: Rand McNally.

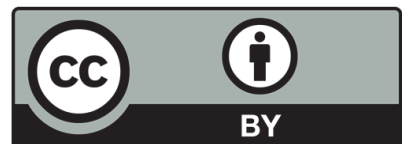

(C) 2016 by the authors; licensee Growing Science, Canada. This is an open access article distributed under the terms and conditions of the Creative Commons Attribution (CC-BY) license (http://creativecommons.org/licenses/by/4.0/). 